\title{
Reactions to \\ "Funding Online Services from the Materials Budget"
}

\section{Sheila Dowd, John H. Whaley, Jr., and Marcia Pankake}

\section{REACTION FROM SHEILA DOWD}

"Then you should say what you mean," the March Hare went on.

"I do," Alice hastily replied; "at least-at least I mean what I say-that's the same thing, you know."

"Not the same thing a bit!" said the Hatter. "Why, you might just as well say that 'I see what I eat' is the same thing as 'I eat what I see'!"

"You might as well say," added the March Hare, "that 'I like what I get' is the same thing as 'I get what I like'!"

The wisdom of Wonderland often seems to address our daily problems; and here I find it applicable to the questions Jay Poole and Gloriana St. Clair have raised. Every library must define its mission, and allocate its available funds for the best accomplishment of that mission. The mission of the academic research library is, as Poole and St. Clair acknowledge, complex; it encompasses the systematic development of collections of scholarly resources, and the provision of services to make those resources available to users of varying degrees of sophistication. The nature of both the collections and the services are changing, and will continue to change with the emergence of new information technologies; but for their own understanding and their accountability to cli- ents and funding sources, library managers must resist the temptation to confuse the two, to blur distinctions and aver that collections and services are the same thing.

At this point it may be well to interject a reminder that the authors themselves have focused this debate on the academic research library and to concede immediately that the question may be irrelevant for those special, public, and college libraries that define their missions entirely in terms of provision of services. The research library is committed to preserving the human record as a resource for scholars now and for future scholarship. The form of that record may change and is changing, but the collection function of the library entails the responsibility to provide information (and its distillation, knowledge, which, as Daniel Boorstin has noted, is orderly and cumulative where information is random and miscellaneous) ${ }^{1}$ for generations of scholars. Thus, for the research library, the principle of building for "probable need" while continuing to address present demand is the essence of the mission and of the challenge. If the book budgets of libraries were limitless or even very generous, the assessment of "probable need" could lead to an inundation of materials, the "vacuum cleaner" approach to collecting. But

Sheila Dowd is assistant university librarian for collection development at the University of California, Berkeley, California 94720. John H. Whaley, Jr., is associate director for collection management at Virginia Commonwealth University, Richmond, Virginia 23284. Marcia Pankake is bibliographer, English literature, at the Wilson Library, University of Minnesota, Minneapolis, Minnesota 55455. 
in fact most collection development librarians are hard pressed to acquire, in sufficient numbers, the works needed for curricular support and for very active research fields and at the same time to anticipate the needs, not of one hundred years hence, but of tomorrow's changing or emerging disciplines. One of the most demanding, skilled, and risky roles in a research library is the role of the selector in anticipating "probable need."

For a research library to attach a higher value to the immediate satisfaction of one patron via an online search than to the development of collections intended to meet the probable needs of changing disciplines and interdisciplinary areas would be regrettable. Conceptually such a value system could be equated with prizing the availability of abundant reserve copies above the creation of a collection reflecting a broad and balanced array of titles. Both activities represent important aspects of the library's mission; but one relates to the library as a service organization, the other to the library as a long-lived resource.

One can nolonger define the building of collections as the amassing of printed sources or even as the acquiring of physical information packages in any form. A "subscription" today may be a fee to a database owner permitting the library to access the files, and, as our authors point out, a journal is no less an important scholarly resource for being published electronically. They are right, too, in suggesting that online indexing will to a considerable extent replace printed indexes as user access systems improve and personal computers proliferate (although most busy reference librarians would tell them that heavy volume of use is still, in the present stage of the technological revolution, best accommodated with the printed index). Where an electronic database does substitute for a printed index, there will be a transfer of costs that certainly must be recognized in budget allocation. What, then, should determine whether an online database cost is properly a collections or a services charge?

The elements of online information services that seem to me to be chargeable to the materials budget are those that provide-whether by purchase, subscription, or contract access-an information resource for the library's entire clientele, or a substantial segment of it. These charges will result in information in electronic mode being equally available to a broad range of library users. The additional costs that may attach to an individual's use of the online service, such as connect costs and database citation charges-that is, those costs that provide service to one individual without providing for any continuing accessibility of the database-are properly considered an element of the library's service function. Poole and St. Clair make the valid point that online indexing may reduce the library's need to process some materials exhaustively in-house. This suggests that the technical services budget too (and the automation budget) should be reviewed when the library is trying to reallocate its funds for the support of online database access.

Subscriptions to electronic journals, then, are a materials budget item; so are subscriptions to online indexes. Purchase of publications on disk or tape are certainly materials acquisitions. One might extend the question further, and add that cooperative purchase of material to be housed elsewhere, in any form, is also an appropriate charge to the materials budget, and hence, at least part of the membership fees in an organization like the Center for Research Libraries, which extends the library's resources through shared ownership, are legitimately chargeable to the materials budget. Fees for interlibrary loan, on the other hand, are, like online connect charges, costs that benefit only one user. They should be treated as part of the library's user services costs.

The authors rightly say that the emergence of computerized access sources has created new costs and additional problems in library budgeting. They speak of libraries that have attempted to meet these costs with "monies raided from already strained operating budgets," and they acknowledge that the final resolution to the problem will be justification to funding agencies of online search costs and acqui- 
sition of permanent funding designated for this use. What they fail to recognize is the fact that their proposed "transition measure" is another form of raid on those strained operating budgets. What is the book budget if not a key element in the library's cost of doing business?

Many of us still believe that citizens are entitled to free access to information and that society has both the duty and the power to provide it. Adequate library support for that goal will not be more readily obtained by absorbing or disguising our needs. The cost of user access to databases is, in the complex of demands associated with the mission of research libraries, a new cost. The pressure for acquisition of publications has not diminished with the new services; indeed, in most libraries demand for publications increases as treasures are unveiled in Dialog or Medline. Demands for the so-called "traditional" library services (and how radically they have changed!) are also increased by the new service capability: more interlibrary loan, more (and more complex) library use instruction, etc. We must recognize that online search services represent competing costs. We must recognize too that they are increasingly vital elements of good library service. We must soberly assess the financial support required to perform our whole mission-the creation of permanent information resources and the provision of efficient access services, and we must convince our funding sources of the urgency of our needs. For a "transition measure" our only choice is to look at the library's total available funds and decide what priority can be assigned to this new need among competitive needs.

The goal of " a democracy of the intellect" is a very difficult and noble one. I take comfort in the thought that there has never been a society more capable of attaining it, if we have the will. To work toward that goal is the first obligation of librarians, and the foundation for that work must be built on a clear, responsible assessment of needs and costs. Let's start by saying what we mean.

\section{REFERENCE}

1. Boorstin, Daniel J. Gresham's Law: Knowledge or Information? (Washington, D.C.: Library of Congress, 1980).

\section{REACTION FROM JOHN H. WHALEY, JR.}

Reduced to the bare essentials, the argument outlined by Jay Poole and Gloriana St. Clair is as follows. Traditionally, libraries have chosen to provide "free" access. Since libraries do not charge, we need to determine which funds at the libraries' disposal will pay for the various services. These services include access to information via the acquisition and processing of materials. Online searching provides a type of access to informationone whose costs are measurable. Since libraries do not charge users for access to traditional formats, they should not charge for access to electronic formats. The authors take the position that online searching should be paid for from the materials budget, and they give reasons to support that stand.

Proposition one-Expenditures for online searches are a clearly identifiable use of the library's funds to support educational and research needs. The purchase of traditional materials represents an investment based principally on guesswork or, as the authors define it, a "probable need." As numerous studies have shown, many titles receive little or no use. Robert Broadus refers to "miles and miles of unread books." The acquisition of these materials results in a warehousing problem that leads ultimately to additional expenditures for storage. The authors argue that since the purchase of materials usually reflects little more than an educated guess on potential use, and that guessing wrong incurs other penalties (long-term storage), a more rational use of the funds would be the purchase of a service of unquestioned educational and research value. For each dollar spent funding online services we would see a defined amount of information provided and used.

Proposition two-" "Libraries have always spent large portions of their budgets on processing and analyzing their materials to make them accessible." If we now spend large sums on acquiring, cataloging, and processing to make information 
accessible, why are we not willing to acknowledge that it is equally reasonable to spend library monies on online searching? "The access provided by online searching is as legitimate a use of funds as the access provided by the processing of materials."

Proposition three-The materials budget should pay for online searching. Already some materials are "published" only in the online format. Will libraries choose not to make this information available simply because it is not published in the traditional mode? Obviously not, since "no administration, internal or external, could question this use of funds."

Proposition four-Having accepted the inevitability of purchasing some "materials" in an online format, libraries should realize the clear advantage of providing the online alternative to some published materials (indexing and abstracting services). In time, full-text downloading will provide a substitute for traditional materials and all guesswork on meeting user needs will disappear, since information would be supplied only on demand. We will have completed the transition from providing information through the purchase of materials to providing information through the purchase of access to databases.

The latter part of the paper treats the implications of funding online searches from the materials budget. Questions related to telecommunications costs; variable distribution of the service to the library's users, by status (undergraduate, graduate, and faculty) and by subject areas (humanities, arts, social sciences, etc.); and possible impact on interlibrary lending are mentioned but not explored in depth. Curiously the authors say nothing about the implications of their proposal on library collections.

For all of the above reasons the authors conclude that the library should bear the cost of the online searches and that the cost should be absorbed by the materials budget.

Now let us examine the first part of the proposal: the library should assume the cost of online searches.

The authors state that "since the expenses of an online search are easily mea- surable, the cost of what has been perceived as a new service has been totally passed on to the user in some cases." What are the components of this cost? The most obvious are the charges for access to the database and for telecommunications and prints, online or batched. Less obvious, but no less real, is the overhead accounted for by the equipment, searcher time, manuals, training workshops, and facilities. No library passes along these latter costs to the consumer because the price would be raised so high that demand for the service would probably disappear. It could be argued that the real expense in the online search is the time of the professionals who prepare and conduct it. This is particularly evident with the less expensive databases such as ERIC and Medline. Thus, even when the library levies a charge for the service, the full cost is not passed on to the user.

To support their contention that libraries should pay for the full cost of searching, the authors draw a parallel between materials processing and online searches. Both are said to facilitate access to information. While it is true that libraries spend large amounts on processing, the money is invested in materials that the library owns and makes available to anyone who needs them. The book on the shelf is there for any user no matter how serious or frivolous the need.

The online search of necessity discriminates against some users, since not all needs are equivalent. Even the most ardent proponent of "free" searches recognizes that there must be some limits imposed. No matter how well reasoned or justified, the limitation will necessarily exclude someone from the benefits of online searching. "It is not like a book, which we buy for everyone to use." Instead we have bought for some privileged users information that, because it is tailor-made, is unlikely to have equal value for other users.

The authors state that the cost of database searching should be borne by the materials budget.

Traditionally we have identified two large components of the budget: materials and operating. Materials budgets pay for tangible items (books, journals, and 
fiche), while operating budgets pay for the costs associated with making materials available to patrons. The introduction of information in new formats arising from advances in technology has created a problem for traditional budget concepts. The information is no longer tangible; that is, there is no "material" for the library to own. Rather, it is in a database that can be accessed by a computer. Therefore, when the information is provided as a printout, the user owns the tangible product. Since the search strategy was designed specifically for that user, the printout of citations is not likely to have value for another researcher. Unlike the book, where multiple uses are possible, the printout is a onetime-use item.

The weakest part of the argument advanced by the authors is that the materials budget should accommodate the expense of online searching. As they have noted, making materials accessible is a legitimate expense, but usually this cost is associated with the operating budget. While the product of an online search may be construed as a "material," the process of conducting the search, including the development of the search strategy and the online interaction with the database, cannot.

Demonstrating the flaws in our selection of print materials does not provide sufficient rationale for using the materials budget to fund online searching. Without convincing evidence that print materials can be justifiably equated with online searches, we must conclude that the materials budget is used because operatingexpense funds are already strained to the limit. This strain has been caused by computer technology, the very technology that the authors wish to make more accessible to the public. The automation of library operations is the new bottomless pit and consumes increasingly greater amounts of the operating dollars. The materials budget is attractive because it has more uncommitted dollars available to fund online searching.

As noted earlier, the authors' discussion omits possible consequences for the collections. Will gaps occur in the collection if funds are diverted to support other services? Something will have to be sacri- ficed. What areas of the collection should bear the cost?

I would argue that the appropriate target should be the reference materials budget: reference items have a high cost per unit; a significant number of them is seldom if ever used. Of those titles frequently consulted, many are regularly superseded and relegated to the general stacks, where they usually collect dust. As the authors note, the paper copies of indexing and abstracting services are often available online; other types of reference material are also being offered electronically. In this format the user has the advantage of currency and greater flexibility in the construction of retrieval termsthey are superior reference tools. As our users become more computer-literate and vendors become more concerned with simplifying access, we should move toward increasingly greater end user service concepts. The skill of the professional searcher should be reserved for complex research problems.

In shifting funds normally expended for reference materials to online searching we must be careful to avoid the temptation to increase the budget for reference materials as an offset to accommodate the new expense. Those who develop reference collections will have to make hard choices between providing reference-type information in traditional or electronic formats. But at least a choice is possible. If we draw online funding from the materials budget at large, the issue is not the substitution of one format for another. Instead, it is the sacrifice of one type of information for another. That is a choice we cannot and should not make.

\section{REACTION FROM MARCIA PANKAKE}

What do we mean when we talk about online services: a subscription to or a lease fee for a database, the connect time to search the data, the fee per citation, purchase or lease of a database on CD-ROM, the search manual, the equipment, or the training workshops? How much of this is paid for by the library budget? How much of this should come, temporarily or indefinitely, from the acquisitions budget? Per- 
haps another perspective on kinds and purposes of permanent and transitory information sources and on library budgets may better illuminate the budgeting question and aid libraries in their goal of facilitating the "democracy of the intellect."

Few question the legitimacy of online access to information or the utility of customized database searches for readyreference facts, lengthy bibliographies, or other information. This function has expanded rapidly in libraries, and demand will continue to grow. But to suggest funding such services from the acquisitions budget implies that they compete with or replace books, serials, and other forms of information. Perhaps the hidden reason for funding online services from the acquisitions budget is that it is always vulnerable. It is an easier target to raid than other parts of the budget, such as those designated for personnel or supplies, in which the staff have vested interests.

We should not decide how to fund online services on the basis of an ill-defined, all-inclusive concept of information. Librarians should acknowledge the varieties and distinctive qualities and uses of different forms of information. Print and electronic media are not interchangeable. They serve different purposes; they have different qualities and characteristics; and librarians should think very carefully about their distinctive functions rather than obscure these differences by lumping all "information" together. Some of these different qualities affect the use of information, for example, the display features-in which the form of the data presentation influences the speed and accuracy of its use, as Tom Norton says when he refers to "the democracy of the printed word" and calls the printed page "a technology ahead of its time."1

Other external factors such as the rapidly changing fee structure for electronic sources, or the power held by those who control the computerized information retrieval systems, may make librarians think carefully about how they use and eventually may rely on these sources and how they justify their funding. Some information scientists suggest that machine- readable information products "pose a threat to the existence of printed information products" because publishers have not found the right pricing structure for these products, and so the industry is still very unstable. ${ }^{\prime \prime 2}$

Online information may not be more economical than print. A printed bibliography or index may be more efficient and cost-effective because it can be used by more than one patron, unlike the individually tailored list of references produced on demand. A book can be used repeatedly and successively and, some argue, at little cost after the first use. ${ }^{3}$

Neither should we justify funding online sources on the basis of the online product's presumed superior utility. Utility is relative to need, and we still know too little about measures and values of utility. The fact that a book or serial is bought at the request of one faculty member or student does not preclude later uses by others, and indeed, the "laws" of sociobiliometrics suggest the opposite. ${ }^{4}$ Jay Poole and Gloriana St. Clair suggest that the purchase of books and other library material is based on speculation, while database searching is not, and that because a search "is precisely defined, the probability of its being used is insured." Thus, presumably, funding database searches may be a "better" use of the acquisitions funds. When, however, is probability ever certain? Just because a search is requested by a patron, or discussed between the patron and the searcher so that it may be "tailored" to a particular need, it does not follow that the search results will be used. Even if every citation is within the scope, the patron may receive the search results and do nothing with them regardless of who has paid. The patron may give up on, lose interest in, or run out of time for the project. Or the search may have provided redundant citations that the patron had identified previously. These duplicate citations are of no use to the patron, but they have cost money. For many reasons, such as unavailability of materials in the library or slowness of interlibrary loan, the patron may not read all the valid sources provided by the online search. The unread citations represent 
lack of use.

Nor should the funding case be argued on the basis of access. The person who unlocks the front door of the library in the morning is providing "access" to information, but no one argues that this activity should be paid for from the acquisitions budget. Whether or not the library underwrites online searches for individuals wholly or partly (and most libraries seem to, in that they absorb the charges for staff time, office space, heat and light), there should be a separate budget to support this service, just as a separate budget should support the "access to information" provided by cataloging, acquisitions, circulation, reference, or interlibrary loan.

The online search may provide access to information, but this information is not added to the stock from which everyone can draw. It is supplied solely to the individual, much like that supplied by reference staff in person or by telephone. Do libraries pay for telephone calls from the book budget?

What the institution buys and the library provides when a printed work is added to the collection is durable information, available to everyone for as long as necessary. Unlike the results of the online search, the reference book represents a permanent addition to the material or capital stock of the library, and the acquisitions budget identifies this portion of the institution's investment. Commercially produced, machine-readable information, which becomes the property of the library, is another expense that may suitably fall under the acquisitions budget.

When custom-made bibliographies or information searches are created and given to individual patrons, this information does not become part of the common property. It does not contribute to a democracy of the intellect in the same way as bound volumes that can be read by anyone. As unique items, the printouts of online searches bear more resemblance to the manuscript painstakingly copied by a monk for a wealthy patron. The democracy of the intellect requires enduring materials available to all, rather than consumable transitory printouts made for private per- sonal consumption or electronic journals available only to individuals with computers, who have no interest in whether the information will be available indefinitely. Certainly we need the latter to stimulate and further the advance of knowledge, but this advance should not come at the direct expense of materials available to any or all users. Librarians must provide the proper mix of media for their patrons and balance print and electronic forms just as they balance other services.

The qualities of malleability, instantaneous change, and potential transience of information in some online databases justify their separation from print materials in the library's budget. As Gordon Neavill has pointed out, the stock of knowledge in the library depends on information recorded in tangible form. ${ }^{5}$ It is libraries, not for-profit vendors, who maintain the availability of information that commercial vendors may find unprofitable: scientific and scholarly information in little or no demand; nonscholarly writings no longer in demand; and noncurrent data purged from updated reference works.

The library budget is both a planning and an operating tool. ${ }^{6}$ One half of budgeting is to get the largest possible amount of money; the other half is to spend that money effectively. The budget should be seen as the tool to seek additional funds to support new services, rather than as yesterday's leftover pie to be divided into smaller and smaller pieces.

Librarians who want to provide vigorous online information services should do it right. The proposal by Poole and St. Clair is a halfway measure to build up the online services. Shouldn't the library instead create a new budget for online services, in order to emphasize this new development? Wouldn't it be better to plan intelligently than to take the easy way out by skimming money off the acquisitions budget? Construct an online services budget that will allow not only for the direct search costs (whether or not any part of these are passed on to the patron) but also for other needs: reference tools like database directories, search manuals, publicity, demonstration searches, ab- 
sorbing of mistakes, training sessions and other costs.

Administrators of institutions often seem to have a preference for funding new or innovative programs. Thus it may be easier to obtain new money for the online service than additional money for an older library operation, and to get this money when the service is new, rather than after it has become entrenched and is regarded as something the library always has done and ought to support without any additional financial help. This strategy may allow online services to compete for money, not internally with books and serials, but externally with other computer services.

One size never fits all, and one recommendation can not apply to all libraries. Some libraries undoubtedly fund online searches from the acquisitions budget. Of course, the budget structure depends on the size and nature of the library. Still, for libraries with large or long-term collections, it seems better not to mix up notions of information, utility, and access with the recognition of expenditures for capital expenses and tangible assets. When online searches are a service, they should be funded as a service. This budgeting allows the library to offer the newest forms of information without weakening the other more solid media through which the democracy of the printed word endures.

\section{REFERENCES}

1. Tom Norton, "Secondary Publications Have a Future in Libraries," Aslib Proceedings 36:317-23 (July/Aug. 1984).

2. Francis $H$. Barker, "Pricing of Information Products," Aslib Proceedings 36:289-97 (July/ Aug. 1984). "International Comparative Price Guide to Databases Online," Online Review 9:333-44 (Aug. 1985).

3. D.I. Raitt, "Electronic Publishing-A View from the Library," Electronic Publishing Review 5:199-210 (Sept. 1985).

4. Stephen Bensman, "Journal Collection Management as a Cumulative Advantage Process," College \& Research Libraries 46:13-29 (Jan. 1985).

5. Gordon B. Neavill, "Electronic Publishing, Libraries, and the Survival of Information," Library Resources \& Technical Services 28:76-89 (Jan./Mar. 1984).

6. Jutta Reed-Scott, "Management of Resources," Collection Management 7:59-67 (Summer 1984). 